\title{
Leituras do espaço rosiano
}

Luis Alberto Brandão I UFMG

Resumo: Este artigo investiga o modo como a categoria espaço é tratada em estudos críticos que abordam a obra literária de Guimarães Rosa. Especificamente, analisa as observações concernentes ao espaço compreendido como categoria empírica, ou seja, como série de referências que, detectáveis pelos sentidos humanos, associam-se a localização, extensão, distância, circunscrição. Tal análise abarca o debate sobre temas como representação, realismo, bumanismo, regionalismo e universalismo.

Palavras-chave: Guimarães Rosa, espaço, realismo, regionalismo.

Este trabalho faz parte de uma investigação sobre o modo como a categoria espaço é tratada nos estudos críticos que abordam a produção literária de Guimarães Rosa. Tomam-se, como corpus de análise, os estudos, de natureza geral ou que se dedicam a obras específicas, reunidos por Eduardo Coutinho na Coleção Fortuna Crítica, os quais se estendem até a década de 70 do século XX. Pretende-se verificar em que medida há, nos textos críticos, algum desenvolvimento teórico da noção de espaço ou de noções de inspiração espacial. Pretende-se, ainda, discutir os aspectos mais relevantes que definem, para o crítico, essa noção, e as formas como é utilizada na qualidade de instrumento de leitura da obra do escritor. Elegendo-se a categoria espaço

1. Todas as citações referem-se a esta obra. 
como referência, indaga-se a maneira como, em determinado período, parte da crítica literária brasileira revela, por meio da interlocução com uma obra literária considerada de vulto, pressupostos teóricos e metodológicos constitutivos da própria noção de "fazer crítico" vigente no Brasil do século XX.

A análise do corpus escolhido revelou quatro tipos principais de leitura do espaço: espaço como categoria empírica, como categoria de linguagem, como categoria mítica e, por fim, operações de inspiração espacial. No presente trabalho, são apresentadas as observações concernentes ao primeiro tipo de leitura, em que o espaço, na qualidade de categoria empírica, é tratado como série de referências que, detectáveis pelos sentidos humanos, associam-se a localização, extensão, distância, circunscrição. Em geral, nesse tipo de leitura, entende-se espaço como sinônimo de espaço físico. Tal abordagem se ocupa seja do reconhecimento e da catalogação dos espaços extratextuais, seja da discussão do modo como se dá a representação de tais espaços no texto.

No primeiro caso, o esforço de reconhecimento pressupõe que discutir o espaço na literatura é descrever a presença do extratextual no textual. Maria Luiza Ramos, em sua "Análise estrutural de Primeiras Estórias", afirma: "As estórias passam-se, na maioria, em ambiente rural, desenhando-se aos nossos olhos as espaçosas casas de fazenda, os quintais, a mata próxima e os grandes descampados. Mas há também a sugestão de lugarejos ou vilas (...) e mesmo centros urbanos..." (p.515). Concomitantemente ao reconhecimento, dá-se a catalogação, operação que revela que a tarefa de descrever o espaço é entendida como a produção de um inventário de suas ocorrências no texto.

A operação catalogadora, no que diz respeito a vários aspectos, é bastante comum na fortuna crítica da obra de Guimarães Rosa. É notável, em muitos textos críticos, a presença de extensas listagens de recursos, especialmente de natureza gramatical. Elas estão na base, por exemplo, dos textos de Oswaldino Marques, intitulado "O repertório verbal"; de Pedro Xisto, "À busca da poesia"; de Eduardo Coutinho, "Guimarães Rosa e o processo de revitalização da linguagem"; e de Lívia Ferreira Santos, "A desconstrução em Tutaméia".

É importante observar que se trata, fundamentalmente, de uma abordagem descritiva, na qual o que poderia haver de analítico tende a se resumir a certo espírito de resolução de enigmas. Parece mesmo haver a tendência, por parte da crítica, de aderir a um papel decifrador, o qual 
provavelmente se justifica por dois fatores simultâneos: por um lado, a extensão da obra de Guimarães Rosa leva a crer que tais recursos são infinitos; por outro, intuição lingüística e um pouco de pesquisa filológica proporcionam resultados rápidos e animadores para o pesquisador. Talvez seja válido, ainda, se estabelecer uma analogia entre o descritivismo verificável na obra de Rosa e o que se constata na leitura desta, o qual se traduz no levantamento de repertórios de recursos (entre os quais, naturalmente, se incluem referências espaciais empíricas - genéricas ou específicas).

Tomando-se o conjunto dos textos críticos que se voltam para o espaço segundo um prisma empírico, observa-se uma posição ambivalente quanto ao valor antropológico da obra literária. Por um lado, valoriza-se a espacialidade empírica. Álvaro Lins, em seu artigo sobre Sagarana, ressalta:

Há outras novelas, porém, que não são da mesma significação nem estão na mesma altura. Embora menos afirmativas como ficção por uma certa fragilidade na ação novelística - "Sarapalha", "Minha gente", "São Marcos" e "Corpo fechado" - ficam valorizadas, no entanto, através de algumas páginas descritivas, ou caracterizadoras como fixação de costumes e episódios isolados, ou, em cada uma delas, através de algum aspecto marcante da vida regional (p.241).

Tal valorização também se observa, nitidamente, no artigo "Aspectos sociológicos de Grande Sertão: Veredas", de Fernando Correia Dias, em que se rastreiam os vários tipos de menções de natureza geográfica.

Por outro lado, entretanto, a crítica observa e censura o que se poderia denominar de "excesso descritivista". Antonio Candido, referindo-se a Sagarana, enuncia: "Seguro de seu feitio, o Sr. Guimarães Rosa despeja nomes de tudo - plantas, bichos, passarinhos, lugares, modas - enrolados em locuções e construções de humilhar os citadinos", acrescentando que seu "sistema fito-zoológico obedece ao critério da Arca de Noé” (p.244). Também em relação a Grande sertão: veredas, Candido menciona os "pendores naturalistas" (p.306). O próprio Fernando Correia Dias admite: "Há exotismo no livro? Provavelmente sim, e isto também é obstáculo para certos gostos”, para em seguida justificar: "Mas, afinal, a paisagem sertaneja - paisagem geográfica e humana - não é bem comportada, para não suscitar o exótico" (p.391).

No segundo caso, a ênfase na concepção empírica de espaço suscita um debate sobre os modos possíveis de representação deste no âmbito 
do texto. Isso equivale a afirmar que, apesar de preservada intacta a concepção empírica de espaço, indaga-se o que ocorre na transposição para a obra literária. Trata-se de perguntar: em que medida há, de fato, descritivismo? Está-se, sem dúvida, no campo das discussões sobre o caráter mimético da literatura. Franklin de Oliveira argumenta: "A Arte imita a Natureza, sim, mas não copiando a natureza, reproduzindo a natureza. Ela a imita, não macaqueando-a, mas agindo por processos idênticos - criando formas mentais como o universo físico cria formas naturais" (p.182). Eduardo Portella, ainda mais explicitamente, defende:

Guimarães Rosa restaura para nós a originalidade da mimese aristotélica. A sua literatura não quer ser nem cópia, nem reprodução da natureza. Nem espelho da natureza, nem segunda natureza. Se nos fosse lícito, afirmaríamos ser ela a terceira natureza. Através da mimese, a arte faz emergir até a plenitude, até o esgotamento, ate a purificação, tudo que a natureza, a realidade ou seu dinamismo, se mostram incapazes de objetivar numa obra (p.200).

O debate se desdobra em duas vertentes, intimamente interligadas: a que se ocupa da questão do realismo e a que discute a feição regionalista na literatura de Guimarães Rosa.

Quanto à primeira questão, constata-se que em geral se atribui à obra uma verve realista, ainda que, em seguida, se tente matizar tal verve de diferentes formas, como pode ser observado, por exemplo, na elaboração de expressões como "realismo mágico", proposta por Euryalo Cannabrava (p.265), "realismo cósmico", por Luiz Costa Lima (p.507), e "realismo poético", por Benedito Nunes, citado por Eduardo Coutinho (p.225). Naturalmente, se é indiscutível que, mesmo que por contraste, se postula o realismo, possivelmente em função da presença ostensiva dos espaços empíricos reconhecíveis, este atua sempre em composição com outras operações, como a imaginação e a criação. Eduardo Portella afirma: "A imaginação organiza a multiplicidade, compõe a unidade, resultando daí a obra: estrutura-se num fluxo contínuo com a percepção, sendo mais fundamental que esta. O que não chega a nos autorizar a entendê-las como dois modos diferentes de assumir-se a realidade. Porque a percepção é a imaginação autolimitando-se" (p.199); Coutinho diz: "A criação é um estágio que fica além da realidade objetiva e o criador é como um sonhador que concebe as suas estórias durante o sono ou nas ocorrências comuns da vida cotidiana" (p.231); e Cannabrava 
adverte, pela via oposta: "Mas o gosto pelo descritivo refreia o ímpeto da imaginação alcandorada, obrigando-a a participar dos pequenos acontecimentos e a disciplinar-se através de incursões constantes no domínio da fisiologia sensorial" (p.265-6).

$\mathrm{Na}$ articulação entre realidade empírica e imaginação criadora, é comum que se defenda a idéia de que a obra de Guimarães Rosa "transcende" a perspectiva realista (p.224). Tal transcendência pode se dar por meio de duas vias. A primeira delas aponta para uma espécie de "realismo da linguagem". Bella Jozef destaca: "O realismo que era horizontal, externo, passou a ser expresso ao nível da linguagem, o que lhe possibilitou uma interiorização, por fazer-se verticalmente, em profundidade" (p.197).

Esta via, na qual o espaço empírico é substituído por um espaço de linguagem, não será abordada neste trabalho. Aqui se enfocará a segunda via que se contrapõe ao realismo descritivista: o realismo humanista. Nesta, o espaço físico passa a ser tomado como espaço humano; no espaço natural, se concebe uma outra natureza: a humana. Nessa passagem, a noção de espaço continua a ser referência, ainda que perca sua especificidade empírica, à medida que lhe é atribuído um valor bem mais abstrato, e, com freqüência, metaforicamente impreciso. Franklin de Oliveira, referindo-se ao poder do artista, enfatiza a "força de criar uma outra natureza, dentro do universo natural. Esta outra natureza tem o nome de universo bumano - a subjetividade, a nossa intimidade, como indivíduo; o da comunidade social em que inserimos a sua existência e o seu destino" (p.182).

A resposta humanista para a questão do realismo pode se manifestar de diferentes modos, ou seja, são sugeridos, como leituras possíveis da obra de Guimarães Rosa, arranjos por intermédio dos quais interagem o espaço natural e o humano, a realidade objetiva e a sua vivência. Esses arranjos são: alternância e simultaneidade; reversibilidade; fusão. No primeiro caso se insere o artigo "A estrutura bipolar da narrativa”, de José Carlos Garbuglio, que retoma, na leitura de Grande Sertão: Veredas, a divisão, proposta por Cavalcanti Proença, entre um plano objetivo e um subjetivo, os quais "se discernem e se implicam mutuamente" (p.422), e aos quais se aliam, respectivamente, a linha diacrônica e a linha sincrônica da narrativa (p.443). O arranjo da reversibilidade é proposto por Antonio Candido: 
Estas considerações sobre o poder recíproco da terra e do homem nos levam à idéia de que há em Grande Sertão: Veredas uma espécie de grande princípio geral de reversibilidade, dando-lhe um caráter fluido e uma misteriosa eficácia. A ela se prendem as diversas ambigüidades que revisitamos, e as que revisitaremos, daqui por diante (p.305).

A reversibilidade já pressupõe, mesmo em Candido, o terceiro arranjo, que é a fusão, assinalada também por Donaldo Schüler: "O homem se expande nas coisas e as coisas inundam o homem. Desaparecem os limites entre o humano e o inumano" (p.366).

Vinculada à questão do realismo, outra questão importante no que tange à categoria espaço, e que é recorrente nas abordagens da obra de Guimarães Rosa, é a do regionalismo. Em linhas gerais, o regionalismo é um tipo de realismo voltado para o que há de particular em determinada região, entendida como uma circunscrição geográfica à qual se associam idiossincrasias sócio-culturais, políticas, econômicas. Aqui, é também a resposta humanista que prevalece, sob a forma de universalismo. Na sua esmagadora maioria, a crítica defende, como Bella Jozef, que na obra de Rosa "o regionalismo adquire significação universal” (p.189). Antonio Candido afirma: "Mas Sagarana não vale apenas na medida em que nos traz um certo sabor regional, mas na medida em que constrói um certo sabor regional, isto é, que transcende a região" (p.244). E ainda, sobre Grande sertão: veredas:

A experiência documentária de Guimarães Rosa, a observação da vida sertaneja, a paixão pela coisa e pelo nome da coisa, a capacidade de entrar na psicologia do rústico - tudo se transformou em significado universal graças à invenção, que subtrai o livro à matriz regional para fazê-lo exprimir os grandes lugares-comuns, sem os quais a arte não sobrevive: dor, júbilo, ódio, amor, morte - para cuja órbita nos arrasta a cada instante, nos mostrando que o pitoresco é acessório e que na verdade o Sertão é o Mundo (p.295).

Tal transcendência pode ser compreendida, também, como uma espécie de humanismo estético. Álvaro Lins destaca que Rosa "apresenta o mundo regional com um espírito universal de autor que tem a experiência da cultura altamente requintada e intelectualizada, transfigurando o material da memória com as potências criadoras e artísticas da imaginação, trabalhando com um ágil, seguro e nobre instrumento de estilo" (p.239). Bella Jozef defende 
que, na obra de Rosa, assim com em alguns outros autores, "há uma fusão de local e universal, do presente e do eterno, com seu conceito de dignidade humana, num ideal de perfeição humana, no sentido atual do termo humanista: 'Uma concepção de vida na qual o homem assume um papel central'” (p.189). Eduardo Coutinho afirma que Guimarães Rosa transcendeu a perspectiva regionalista "e penetrou muito mais fundo na realidade humana" (p.224).

Observa-se, assim, que a própria noção de humanismo é oscilante: pode significar a utilização de um meio de expressão elevado (Rosa transcenderia o regionalismo por utilizar uma linguagem de inspiração universal); a abordagem de experiências comuns a todos os seres humanos (Rosa extrairia, de experiências particulares, significados gerais); e a ênfase na importância da condição humana, segundo um certo ideal (Rosa colocaria, no cerne de sua obra, o homem).

Para que seja viável o realismo humanista de Rosa, que não deixa de ser uma forma de idealismo, é necessário que se suprima um termo que, nesta coletânea crítica, tem pouca repercussão. Esse termo é história. Roberto Schwarz afirma: "Em Grande sertão a História quase não tem lugar - o que não é defeito; dentro das proposições do livro é virtude. Enquanto em $D r$. Faustus a trama, no seu caminho para os valores universais, passa detidamente pelo destino alemão, em Guimarães Rosa a passagem da região para o destino humano, tomado em seu sentido mais geral possível, é imediata”. Em função disso, o crítico conclui: "Esta ligação direta desobriga o autor de qualquer realismo, pois o compromisso assumido pouco se prende à realidade empírica" (p.389). Se o provocante raciocínio é válido, pode-se dizer que, a partir da negação à ênfase empírica do espaço, mediante sua humanização, chega-se não a um espaço historicamente humano, mas a um espaço idealizado, ou seja, que recusa a circunscrição histórica, espaço que se configura segundo a prevalência de uma chave mítica.

Finalmente, considerando-se o corpus escolhido, que não é exaustivo e cobre somente um determinado período, e no que diz respeito à abordagem do espaço empírico na obra, pode-se levantar a hipótese de que a crítica tende a se distribuir entre a atitude descritivista (no caso dos críticos que tomam como importante - ainda que não definam com clareza o porquê - a referencialidade empírica da obra) e a idealizadora (que aborda a obra segundo um parâmetro, ainda que variável, de universalidade; ou segundo o critério da genialidade do autor). Em ambos os casos, elimina-se o esforço de 
compreender, historicamente, a literatura. Contentar-se com a mera descrição da obra, por um lado, ou rejubilar-se, de forma mais ou menos apologética, com sua idealização, por outro, são modos de não colocá-la sob prisma histórico. Utilizar tal prisma corresponde a demonstrar que nenhuma obra, por mais grandiosa e penetrante, é genial, já que é, precisamente, síntese de formas tipicamente históricas.

Abstract: This paper investigates how space as category is explored in critical essays that study Guimarães Rosa's literary work. Specifically, analyses remarks concerning space understood as empirical category, as a series of references perceivable by human senses and which are related to localization, extension, distance, circumscription. Encloses the debate on themes like representation, realism, humanism, regionalism and universalism.

Key words: Guimarães Rosa, space, realism, regionalism.

\section{Referência Bibliográfica}

COUTINHO, Eduardo (Org.). Guimarães Rosa. $2^{2}$ ed. Rio de Janeiro: Civilização Brasileira, 1991. 580 p. Coleção Fortuna Crítica. 